\title{
When does a fetus become a person? An Israeli viewpoint
}

\author{
Nitzan Rimon-Zarfaty, ${ }^{1}$ Aviad E Raz, ${ }^{2}$ Yael Hashiloni-Dolev ${ }^{3}$
}

'PhD Candidate, Department of Sociology and Anthropology, Ben-Gurion University of the Negev, Beer-Sheva, Israel

2Professor of Sociology, Department of Sociology and Anthropology, Ben-Gurion University of the Negev, Beer-Sheva, Israel

${ }^{3}$ Senior Lecturer in Sociology, School of Government and Society, Academic College of Tel-Aviv Yaffo, Yaffo, Israel

\section{Correspondence to Nitzan Rimon-Zarfaty, Department of Sociology and Anthropology, Ben-Gurion University of the Negev, Beer-Sheva 84105, Israel; rimonn@bgu.ac.il}

Received 6 July 2010 Accepted 28 March 2011 Published Online First 6 July 2011

\begin{abstract}
Background and methodology 'Biological' and 'human' life or 'personhood' are not necessarily identical. While the Catholic Church does not separate the two, concluding that human life commences at conception, Judaism endows the fetus with personhood gradually throughout the pregnancy. Gradualism is also reflected in many Western abortion laws that prohibit 'late abortion'. Importantly, the Israeli law does not prohibit abortion at any stage of pregnancy. To examine attitudes regarding the status of the fetus vis-a-vis its stages of development, a questionnaire presenting ten successive stages was distributed to Israeli respondents $(n=281)$. For each stage participants were asked to grade the fetus as having 'personhood' or as a 'living organism' on a five-point scale. Data were analysed to show frequency distribution. Results The fetus gains its ascribed personhood gradually. Most of the participants perceived the fetus as a person at the stage in which the woman feels its movements. Additionally, many (especially secular respondents) evaluated the fetus as a living organism at earlier stages, thus making a distinction between the fetus as a living organism and as a person. An international comparison with Englishspeaking countries revealed a local 'Israeli' tendency to attribute personhood status to the fetus only at a relatively late stage. Discussion and conclusions The 'Israeli' fetus acquires its status gradually. This finding challenges the dichotomous conceptualisation of the fetus as 'a person' or 'non-person'. The authors conclude by presenting the perceived transformation of the fetus to 'personhood' as being influenced by national and religious factors.
\end{abstract}

\section{Introduction}

When does the fetus acquire a social recognition of its moral standing and is thus perceived as being a person holding rights who deserves to be protected? This question, which formed the impetus for this study, has received various answers from

\section{Key message points}

The Israeli fetus gains its status as a person gradually, and is perceived as 'a person' in the fetal movements stage.

> Respondents made a distinction between the fetus as a living organism and as a person.

> An international comparison revealed an 'Israeli' tendency to attribute personhood status to the fetus at a relatively late stage.

Our study challenges the dichotomous conceptualisation of the fetus as 'person/non-person', focusing on this issue as a gradual transformation influenced by national and religious factors.

philosophers, bioethicists, medical legislators and laypeople. It is also embedded in various sociocultural contexts including religion and nationality - this study focuses on the Israeli context.

Previous research regarding the moral standing of the fetus in Israeli society has concentrated on health professionals,,${ }^{12}$ the dynamics of legal and political governance, ${ }^{3-6}$ and patients' organisations. ${ }^{7}$ However, studies regarding public opinion on this matter are sparse. This study describes, for the first time, attitudes in Israel regarding three main issues: (1) 'biological' status versus 'personhood' status, (2) the gradual acquisition of personhood (i.e. a status of holding rights that deserve to be protected) and (3) the gestational stage in which the fetus is perceived as being a person.

\section{Overview of attitudes about key \\ issues}

Perceiving life as having 'biological' and/or 'personhood' status

Life in its biological essence (i.e. the stage at which the fetus becomes a living organism) and in terms of being a person are not necessarily perceived as identical. According to one viewpoint, which sees a close connection between the two, it is a biological event (e.g. insemination, fetal heartbeats, viability, or even birth) that confers personhood on the fetus. ${ }^{8-11}$ Singer argues for an opposite approach in claiming that there are "two distinct notions: 
membership of the species Homo sapiens, and being a person, in the sense of a rational or self-conscious being". Singer claims that while a fetus is a "member of the species Homo sapiens" it is not a person. As a defender of abortion, Singer argues that "we should look at the fetus for what it is - the actual characteristics it possesses - and value its life accordingly". According to Singer, even a newborn is not a person since it lacks "rationality, autonomy and self-consciousness". ${ }^{12}{ }^{13}$ A similar distinction was made by Dworkin,${ }^{14}$ who separated between what he referred to as derivative objection to abortion - which regards the fetus as a person with human rights and interests (including the right not to be killed); and detached objection to abortion, which emphasises the sacredness of human life in itself (from the moment biological life begins) without viewing the embryo/fetus as an entity bearing interests and rights.

The Roman Catholic Church identifies biological and personhood status as one, commencing at conception, and thus abortion is strongly opposed. As regards other religions in the USA (including North American Jews, but mainly Christians), Evans and Hudson argue that the more religious people are, the more opposed they are to reproductive genetic technologies. ${ }^{15}$

Approximately $75 \%$ of the Israeli public is Jewish. ${ }^{16}$ In studies conducted in the USA, Jews generally expressed a relatively positive attitude towards abor$\operatorname{tion}^{17} 18$ and therefore did not perceive the life of fetuses as sacred. Furthermore, it has been found that Jews generally believed that prenatal diagnosis (which may lead to selective abortion) is beneficial. ${ }^{19}{ }^{20}$ This difference is arguably connected to the level of religiosity and is empirically tested in this study.

Secular Jews in Israel have been characterised as generally pro-eugenic. ${ }^{121-24}$ The Israeli law allows for abortion due to fetal abnormalities, even at a late stage and for mild or probable abnormalities. ${ }^{125} 26$ In fact, the Israeli abortion law does not provide the fetus with legal status or protection. ${ }^{1227}$ Amir and Shoshi ${ }^{28}$ have noted that in contrast to public controversies in other countries, there has been no public debate regarding fetal rights in Israel. (See, however, Weiner and Hashiloni-Dolev ${ }^{29}$ for a micro-analysis of the debate. This analysis suggests that while the declarative level of the Israeli law and following policy regards the fetus as holding no legal and moral personhood or rights, ${ }^{27}$ on the personal, micro-level the debate is more ambivalent. Weiner and Hashiloni-Dolev found that medical professionals' perceptions of the fetus tend to derive from its relevant familial relationships - mainly the way in which the mother relates to the fetus - and therefore are relationally embedded.)

\section{The personhood status of the fetus as being gradually acquired}

The question of abortion is vehemently debated among Jewish rabbinical authorities. Steinberg ${ }^{30}$ identifies a change in the character of those debates according to the fetal developmental stages. Indeed, Jewish law (halacha) is understood by some rabbinical authorities to endow the fetus with personhood only gradually throughout the evolvement of the pregnancy. ${ }^{30}$ According to the accepted interpretation of Jewish writings, until the 40th day after fertilisation (in which the soul is believed to enter the body) the embryo is considered nothing but water. It should be noted that in surveys conducted in the English-speaking world, this gradualist perception was also found among laypeople who are not Jewish. ${ }^{31}$ ${ }^{32}$ Indeed, many Western abortion laws are based on a perception of stages in pregnancy. Furthermore, many of the laws prohibit 'late-abortion' - after the stage of fetal viability (Weeks 23-24 of pregnancy). ${ }^{33}$ Importantly, the Israeli abortion law does not prohibit abortion at any stage of pregnancy ${ }^{3435}$ Nonetheless, in a secondary legalisation (memorandum \#23/07, issued 19.12.07) ) $^{34}$ the Israeli Ministry of Health decided that in order to justify late-term abortions (beyond Week 24), the embryopathy must be medically considered 'severe' as well as probable (probability $>30 \%$ ) when discussed by a special hospital committee.

\section{The stage at which the fetus is perceived as having personhood status}

Kalfoglou $e t a l^{31}$ found that the stage at which the majority of USA participants accorded the fetus personhood status was the heartbeat monitoring stage (Week 8 of pregnancy). In another international survey that compared English-speaking countries (USA, UK and Australia,), participants were asked about the beginning of life in its biological sense. Similarly, the highest percentage of respondents $(23.5 \%)$ chose the heartbeat monitoring stage. ${ }^{36}$ Our study also examined the stage at which the majority of Israeli participants perceive the fetus to be a living organism and when they regard it as a person - and whether these stages differ from those found in studies done in other nations.

\section{Methodology}

The two questions we presented in the questionnaire (which was written in Hebrew) were as follows:

1. According to your opinion, in which of the following stages does life begin, biologically speaking (i.e. a living organism has been created)?

2. According to your opinion, at which of the following stages (if at all) a person is created, that is, an autonomous entity whose life should be protected by the law?

Following each of these questions, we presented ten successive stages of embryonic/fetal development (see Appendix 1 for the full list). Most of those stages (seven out of ten) were chosen based on stages used in other studies $^{3136}$ in order to enable a comparison. Additional stages were added based on relevant literature that emphasises the Israeli prenatal diagnosis routine and highly medicalised pregnancies. ${ }^{21}$ Therefore we added 
Table 1 Demographic details of study participants (undergraduate students, $n=281$, average age 23.8 years).

\begin{tabular}{|c|c|}
\hline Demographic detail & Percentage (\%) \\
\hline \multicolumn{2}{|l|}{ Gender } \\
\hline Male & 16 \\
\hline Female & 83 \\
\hline NS & 1 \\
\hline \multicolumn{2}{|l|}{ Marriage status } \\
\hline Single & 94 \\
\hline Married & 5 \\
\hline NS & 1 \\
\hline \multicolumn{2}{|l|}{ Parental status } \\
\hline Childless & 98 \\
\hline Parents & 1 \\
\hline NS & 1 \\
\hline \multicolumn{2}{|l|}{ Religion } \\
\hline Jewish & 96 \\
\hline Muslim & 1.5 \\
\hline NS & 2.5 \\
\hline \multicolumn{2}{|l|}{ Religiosity } \\
\hline Secular & 78 \\
\hline Traditional Jewish* & 17 \\
\hline Orthodox Jewish* & 4 \\
\hline NS & 1 \\
\hline \multicolumn{2}{|l|}{ Birthplace } \\
\hline Israel & 86 \\
\hline USSR & 9 \\
\hline Ethiopia & 1 \\
\hline Other countries & 3 \\
\hline NS & 1 \\
\hline
\end{tabular}

the stage of the appearance of human morphology and the stage of estimation of the fetus' weight experienced through ultrasound scans. In addition, due to Weiner and Hashiloni-Dolev's ${ }^{29}$ emphasis on the importance of subjective (maternal) perceptions of the fetus in constructing its moral standing, we added the stage of fetal movements. Another reason for adding this stage is its historical importance: before the existence of modern technology the stage of 'quickening' was socially perceived as a turning point in the perception of the pregnancy as well as the fetus' standing. ${ }^{29} 3738$ Therefore the terminology used in defining the stages was based on the terminology used in previous studies (e.g. the connection to new reproductive technologies (NRTs) in the earliest stages), the need to combine the (not always identical) stages used in those works, and the typical 'Israeli' perspective and terminology. For each stage participants were asked to grade the level of 'personhood' or 'viability' of the fetus on a five-point scale $(0 \%, 25 \%, 50 \%, 75 \%$ and 100\%). In addition, participants were asked for demographic details (Table 1).

For the purposes of this exploratory study (conducted during the period January-April 2009) we used a convenience sample of 281 undergraduate students attending undergraduate courses and from four different Israeli academic institutions (Ben-Gurion University, Tel-Aviv University, Academic College of Tel-Aviv Yaffo, Achva College). Students were from the psychology, sociology and anthropology, or behavioural sciences departments. All participants were asked to sign an informed consent form, which ensured full anonymity. Respondents had no introductory lecture/information regarding the different stages of embryonic/fetal development. Questionnaires

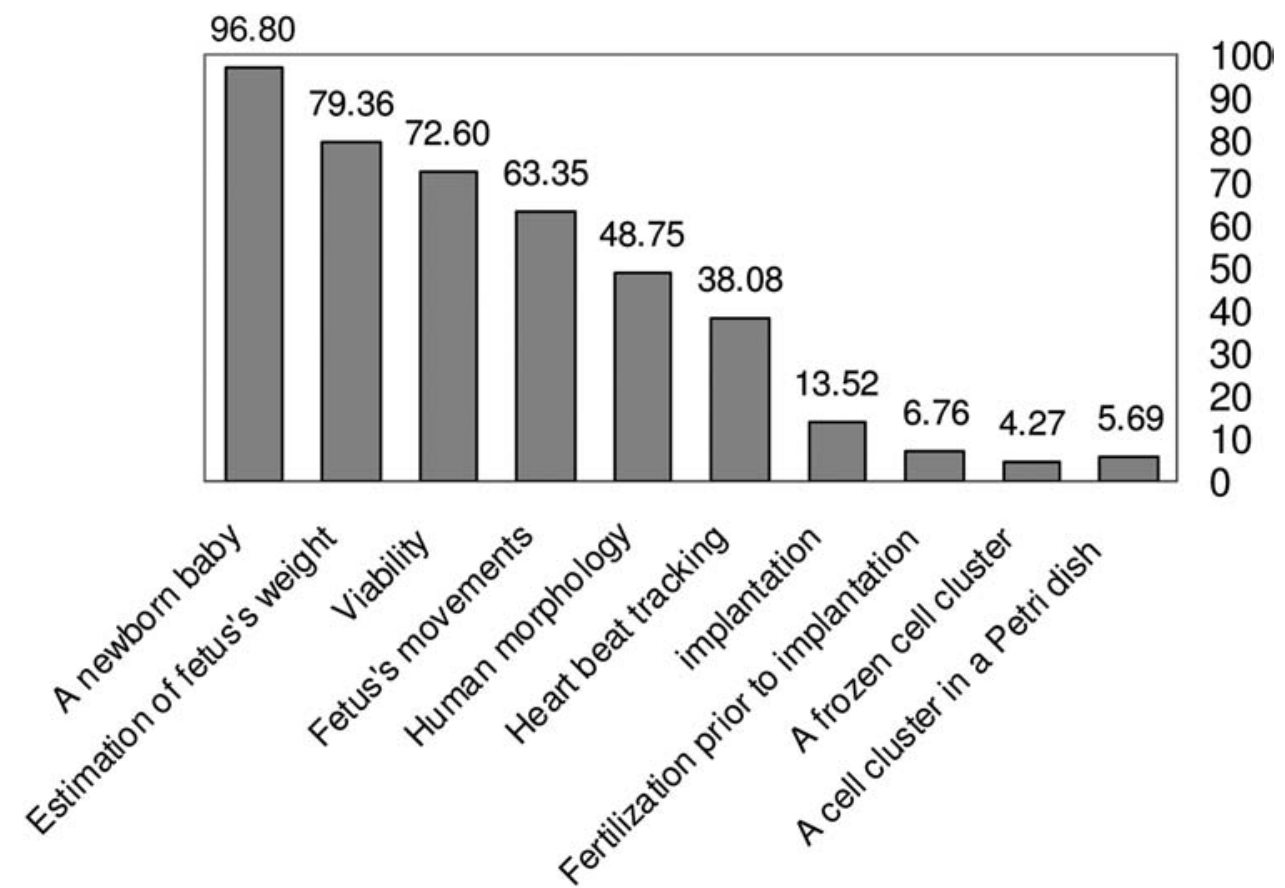

Figure 1 Participants (in percentages) who assigned the fetus a personhood status by choosing the two high levels in the grading scale $(75 \%$ and $100 \%)$, according to developmental stage. 
were completed individually. Almost all the respondents (close to 100\%) completed the questionnaire.

\section{Statistical analysis}

Data were analysed using Excel ${ }^{\mathrm{TM}}$ software to show the frequency distribution. The analysis examined the percentage of the participants who chose each of the options on the scale (what percentage chose $0 \%, 25 \%$, $50 \%$, and so on). During the second stage, the percentages of the participants who gave the maximal values (i.e. $75 \%$ and $100 \%$ ) were combined and are presented in the Results section.

\section{Results}

\section{Progressive acquisition of personhood status}

The major finding is that the fetus gains its personhood status gradually: the higher its developmental stage, the more it is perceived as a person (Figure 1). The absolute majority of the participants did not perceive a cluster of cells as having personhood status. The fetus' heartbeat tracking stage as giving personhood status $(38 \%)$ showed a rise in the percentage of the graders. From this stage on, there was a consistent and clear rise in the percentage of graders of the fetus giving personhood status. This stage, it should be noted, approximately fits the Jewish view of the embryo/fetus as starting to acquire personhood status at 40 days of conception. The change between the stage where it is possible to evaluate the fetus' birth weight (79\% agreement) and the newborn stage (with 97\% agreement) shows that many of the respondents perceived the fetus as a person only postpartum. It should be noted that approximately $3 \%$ of the participants did not perceive even a newborn baby as a person, perhaps similar to Singer's ${ }^{12} 13$ viewpoint.

The majority $(63 \%)$ of the participants perceived the fetus as being a person when the pregnant woman starts to feel fetal movements. In contrast, the stage at which the majority (72\%) of the participants perceived the fetus as a living organism was the heartbeat monitoring stage (Figure 2).

\section{Differences in the conceptualisation of biological and personhood status}

The data show a clear division between the stages that precede the fetus' heartbeat tracking stage (Stage 5), at which the majority of the participants did not perceive the fetus as a living organism, and the fifth stage on, at which the absolute majority perceived the fetus as a living organism. In the fifth stage the majority of the participants perceived the fetus as a living organism yet almost half of them did not perceive the fetus as a person (Figure 2).

\section{Influence of religiosity}

As part of our analysis (and due to the small number of Orthodox participants) we have created the category 'Religious' (Box 1). This category includes both Orthodox as well as traditional participants. Traditionalist is a unique Israeli definition of a person who believes in God and generally follows and respects Jewish tradition and customs, but is less committed to fully operate according to them than is an Orthodox person.

A difference was found between secular and religious Jews regarding the two questions. The second question presented the largest difference (15\%). During almost
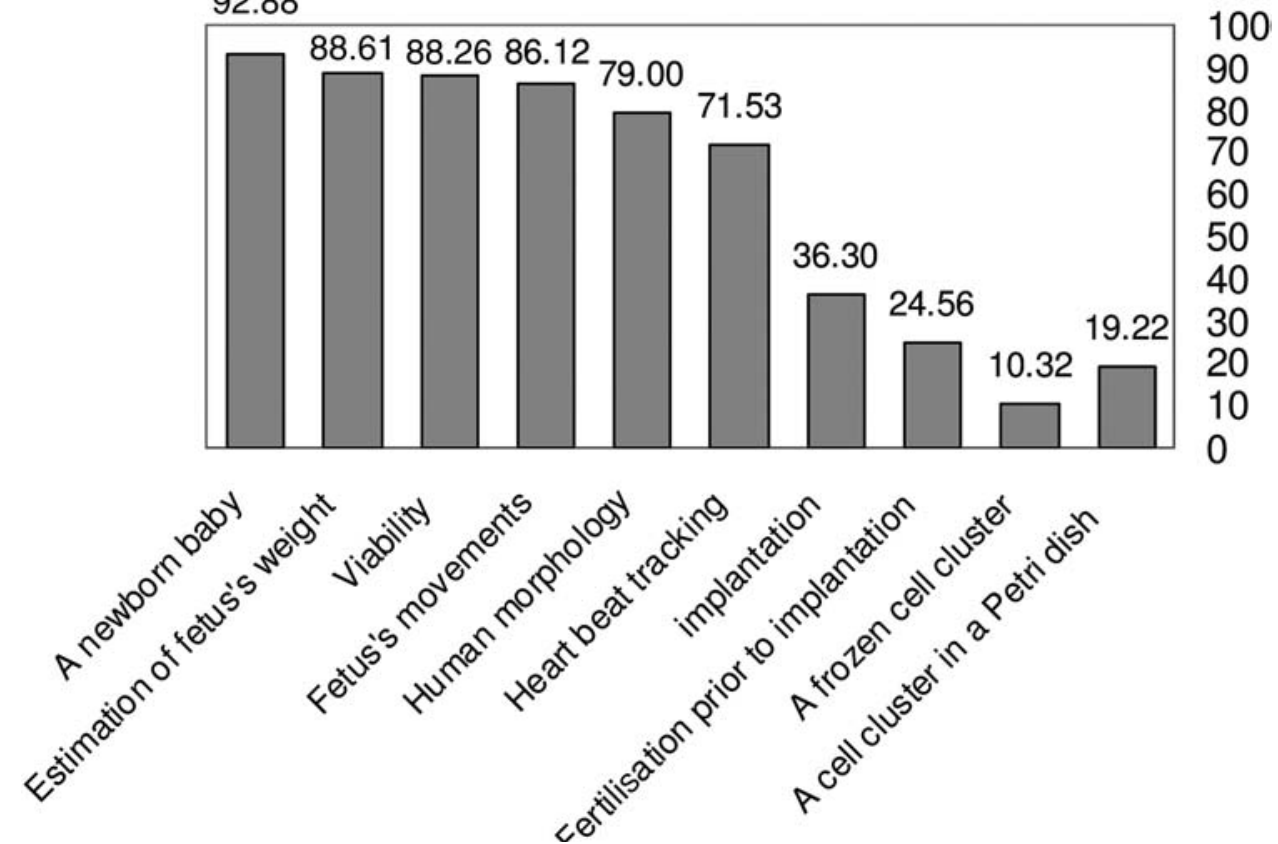

Figure 2 Participants (in percentages) perceiving the beginning of life in its biological sense according to the fetus' developmental stage. 


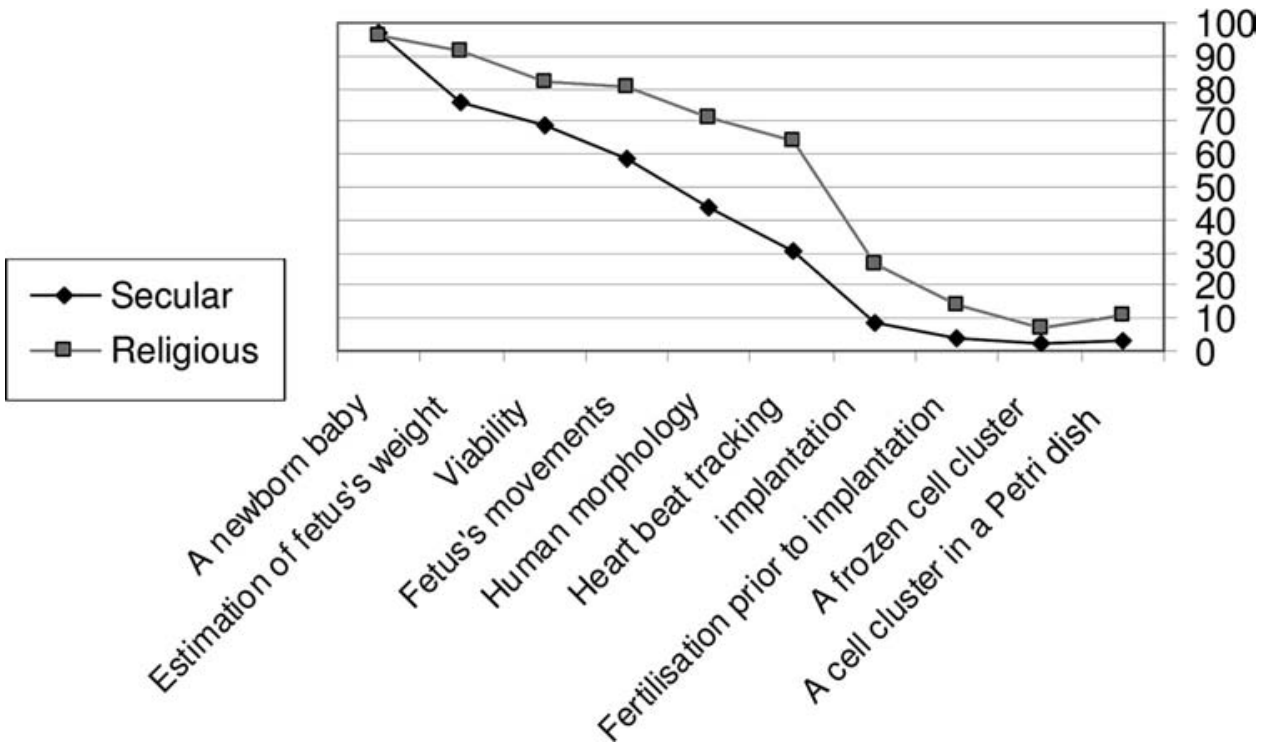

Figure 3 Participants (in percentages) who assigned the fetus a personhood status, according to developmental stage and their religiosity.

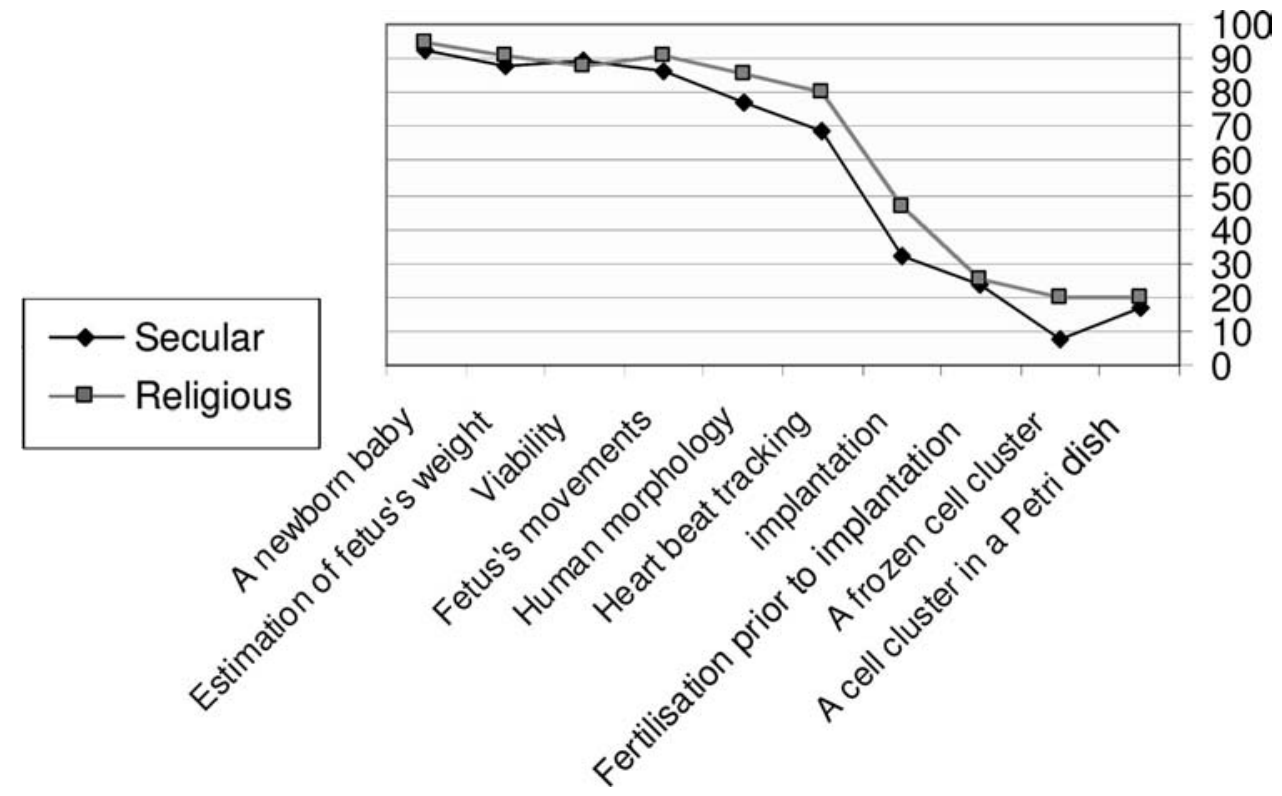

Figure 4 Participants (in percentages) perceiving the beginning of life in its biological sense according to the fetus' developmental stage and their religiosity.

all of the stages, the percentage of religious respondents who perceived the fetus to have personhood status was substantially higher in relation to secular respondents (Figure 3).

While the gradual change was preserved among secular respondents, among religious respondents the fetal heartbeat tracking stage was the turning point from which the fetus was defined as a person. This attitude embodied the largest difference between religious and secular respondents. In contrast, the majority of the secular respondents graded the fetus as having personhood status at the stage of fetal movements. As a possible interpretation of this finding (which calls for further research of the relevant positions) one may assume that whereas religious respondents relied on an 'objective' parameter (e.g. the ability to trace fetal heartbeats), secular respondents relied more on the pregnant woman's experience of fetal movements. The question of the biological beginning of life presented a smaller difference (an average of 6\%) between religious and secular respondents, at all stages, in the assigning of maximal values (Figure 4). This suggests that the secular participants made a bigger distinction between the fetus as a living creature and the fetus as a person than did the religious participants.

\section{International comparison}

A comparison with studies performed in the Englishspeaking world (i.e. Australia, USA and UK) (which, 


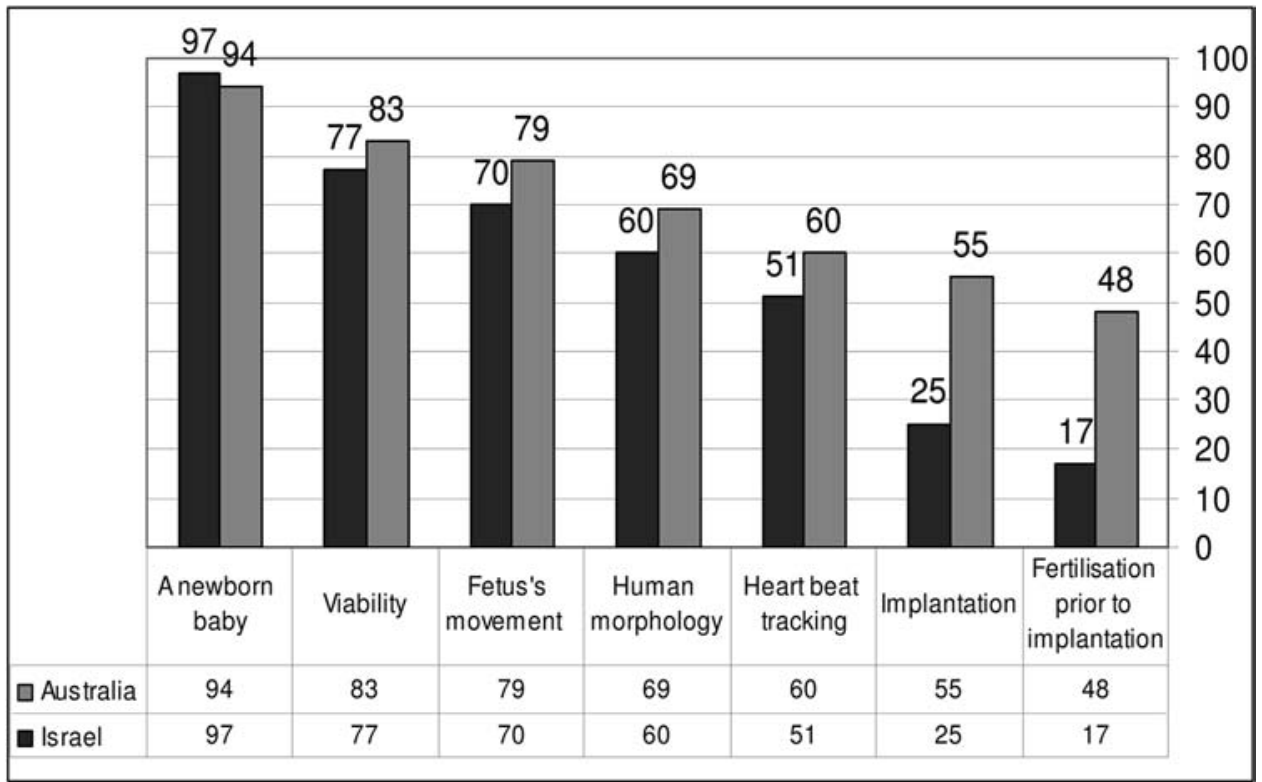

Figure 5 The average grading of the fetus's personhood according to developmental stage: a comparison between Australia and Israel. [NB. In cases in which there was no exact parallel between the stages used in the Australian study and our study, we used the closest stage found. The Australian study presented the average value of the scaling in relation to each stage rather than frequency distribution. In order to enable the comparison, we calculated the average values in the Israeli sample also.]

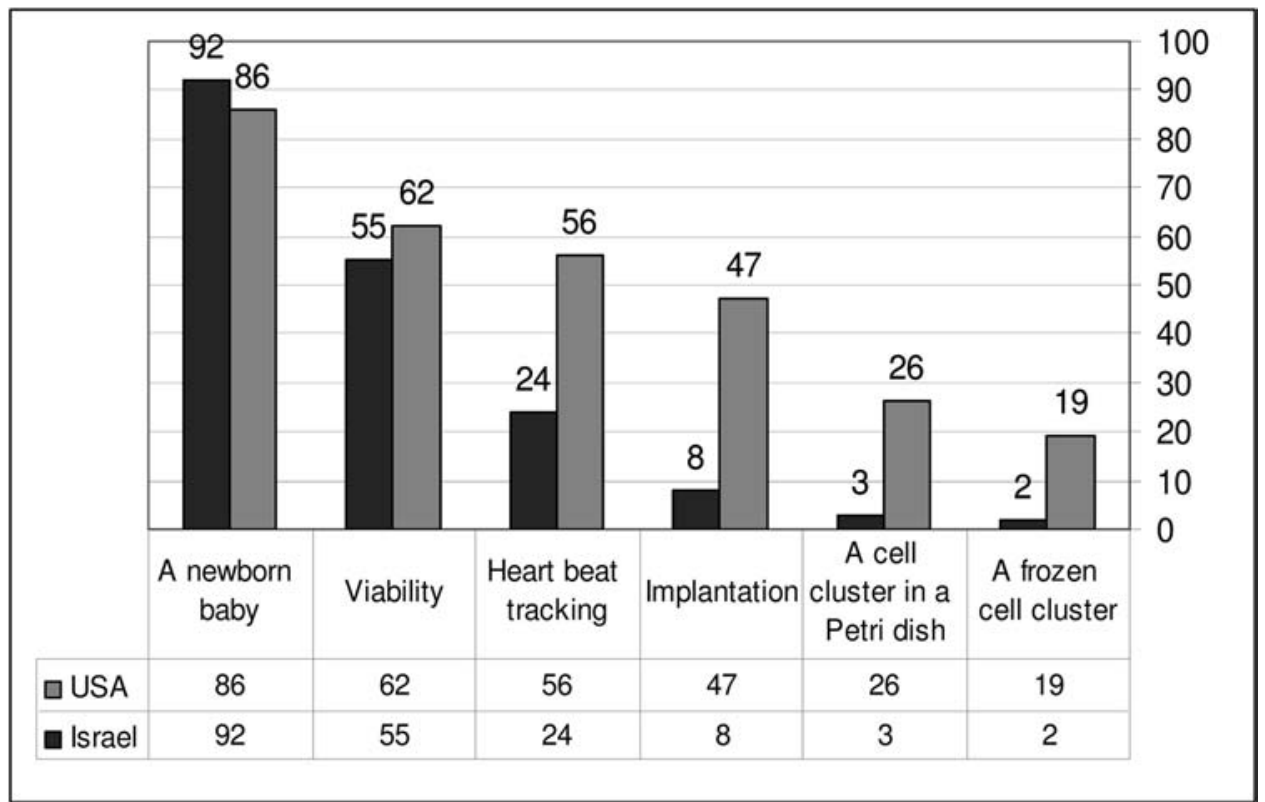

Figure 6 Participants (in percentages) who attributed a personhood status to the fetus (i.e. chose the highest levels on the grading scale) according to the developmental stage: a comparison between the USA and Israel. [NB. Kalfoglou et al. ${ }^{31}$ referred solely to the highest level in the grading scale and not to the two high levels as we did. Therefore, for this comparison, we refer only to the highest level on the grading scale on the Israeli sample.]

unlike our study, used general public samples) raises a number of interesting issues. Participants in the Australian study performed by Kelley and Evans ${ }^{32}$ were asked to grade the fetus' personhood along various developmental stages, on a five-point scale. The Australian study also found a gradual increase in respondents' assigning personhood status to the embryo/fetus; however, in contrast to this study, Australian respondents assigned more (9-30\%) personhood to the embryo at the early developmental stages (Figure 5).

Kalfoglou et al..$^{31}$ also found a gradual increase in USA respondents' assigning personhood status to the fetus, again with considerably more USA respondents assigning this status to the embryo at the early developmental stages (Figure 6). Only in the last stage (that of newborn) there were slightly more Israelis, in relation 
to the Australian and the American respondents, who perceived the fetus as a person.

Research, ${ }^{36}$ comparing attitudes in the USA, UK and Australia, found that - in a similar manner to our findings $-23.5 \%$ (the highest percentage of respondents) chose heartbeat monitoring as the point at which life begins biologically. Fewer than 23\% chose fertilisation and $15 \%$ chose the fetus' implanting in the womb wall. It was also found that Catholic respondents had the highest percentage (31\%) of choosing the earliest stage ('spermegg fusion') as the stage at which biological life begins. In contrast, $33 \%, 29 \%$ and $27 \%$ of the Jewish, secular and Muslim respondents, respectively, chose the fetus' heartbeat as the stage at which biological life begins.

\section{Discussion}

Several preliminary conclusions can be drawn from the analysis of our findings in comparative perspective, serving as a basis for larger-scale data collection to be conducted in future studies. First, in this Israeli study of university (yet unprofessional) students there is a tendency to attribute personhood status to the fetus only at a relatively late stage. Therefore, there is a correlation between their opinion and the Israeli law that provides a relative broad leeway for selective abortion within the conditions it prescribes. Israeli respondents, in contrast to USA and Australian respondents, were much less disposed to assigning personhood status to the fetus during the early developmental stages. While most Israeli respondents attributed personhood status to the fetus in the fetal movements stage (Weeks 16-20), this was done by the majority of the American participants at a much earlier stage of the fetus' heartbeats (Week 8). Thus our findings suggest that ideas about the fetus are deeply contested and are based as much on cultural norms as on biological status. Israeli society has been described/ criticised as disregarding the moral and legal status of the fetus ${ }^{122728}$ until a relatively late stage when the pregnant women can subjectively feel its movements. ${ }^{29}$ Our study provides new empirical data that substantiate this claim. This data also contribute to our understanding of the Israeli 'permissive' policy towards stem cell research, prenatal diagnosis and selective abortion, which in contrast to many Western countries are not conceptualised as posing a moral or societal threat. ${ }^{39}$

Our data may be explained in the light of the Jewish tradition, where the fetus acquires its status gradually. Furthermore, basic Halachic texts (e.g. the Mishnah as well as the Babylonian Talmud) can be interpreted as arguing that personhood status (Hebrew term: nefesh) with all human rights is granted only after birth (or more precisely: during the birth process, when the bigger part of the child is born). ${ }^{40}$ This is in contrast to the position of the Catholic Church whereby full personhood begins at conception. In addition, as was mentioned earlier, according to Jewish tradition, until the 40th day after fertilisation the embryo is considered to be only water. This may explain our finding which suggests that the biggest difference between the Israelis, in comparison to the Australian and the North American respondents, is when they ascribe personhood status to the embryo/fetus.

Our findings, which offer a comparative basis for examining religious and national perspectives on bioethical issues, can be further developed in future studies. Directions for future studies include, for example, cultural scripts such as the Israeli predilection for pro-natalism and the national importance of fertility, ${ }^{41}$ described as leading to an enthusiastic acceptance of NRTs that are also strongly supported by the state. ${ }^{42}$ Such uncritical acceptance of NRTs may correlate with the data that suggest that the 'Israeli' preimplantation embryo is not a person. Furthermore, Israeli society has been identified as generally trustful of science and technology, which is perceived to guarantee its existence in a hostile environment. ${ }^{43}$ The status of the 'Israeli' fetus also reflects (and is reassured by) the Israeli legal system, which endows human beings with full legal rights only post partum, ${ }^{27}$ considers some life to be 'wrongful', ${ }^{1}$ and allows late-stage eugenic abortions. ${ }^{125-27}$

Second, the findings throw into relief how, for many Israeli respondents, the standing of the fetus is a process rather than a sudden change. This is in contrast to the philosophical and legal discussion that typically defines personhood as a dichotomous, either/or concept. ${ }^{15} 32$ Casper argued that fetuses are situated in "the margins of humanity", and therefore their status and identity are often liquid and hybrid in relation to the constructed categories of 'human' (a moral status of a person) versus 'non-human', thus challenging this dichotomous duality. ${ }^{44}$ In the light of this more complex picture, it would be a mistake to define the Israeli concept of the fetus as 'non-person'. According to our findings the fetus acquires its status gradually.

In addition, many of the participants in our study made a distinction between the fetus as a living creature and the fetus as a person, claiming that even if one can perceive the fetus as a living creature this does not attribute personhood status to it (the distinction was more prominent among secular respondents).

Our study enables a more complex reflection on the issue, especially by challenging the conventional conceptualisation of the fetus in dichotomous terms as a person or non-person, focusing instead on this issue as a gradual change that is conceptualised differently depending on social and religious influences.

Acknowledgements An earlier version of this paper was presented at the XVII ISA World Congress of Sociology: 'Sociology on the Move' held in Gothenburg, Sweden, 11-17 July 2010.

\section{Competing interests None.}

Provenance and peer review Not commissioned; externally peer reviewed. 


\section{References}

1 Hashiloni-Dolev Y. A Life (Un)Worthy of Living: Reproductive Genetics in Israel and Germany. Dordrecht, The Netherlands: Springer, 2007.

2 Hashiloni-Dolev Y. Between mothers, fetuses and society: reproductive genetics in the Israeli-Jewish context. Nashim 2006;12(Fall):129-150.

3 Amir D, Binyamin O. Abortion approval as ritual of symbolic control. In: Feinman C (ed.), The Criminalization of Women's Body. Binghamton, NY: Haworth Press, 1992;5-25.

4 Amir D, Binyamin O. The abortion committees: educating and controlling women. Women Crim Justice 1992;3:5-25.

5 Gooldin S. Technologies of happiness: fertility management in a pro-natal context. In: Yona Y, Kamp A (eds), Citizenship Gaps: Migration, Fertility and Identity in Israel [in Hebrew]. Jerusalem, Israel: Van-Leer/Hakibutz Hameuhad Publishing, 2008;167-206.

6 Hashiloni-Dolev Y, Shkedi S. On new reproductive technologies and family ethics: pre-implantation genetic diagnosis for sibling donor in Israel and Germany. Soc Sci Med 2007;65:2081-2092.

7 Raz A. 'Important to test, important to support': attitudes toward disability rights and prenatal diagnosis among leaders of support groups for genetic disorders in Israel. Soc Sci Med 2004;59:1857-1866.

8 Heyd D. Ethics and Medicine [in Hebrew]. Tel Aviv, Israel: The Transmitted University, Ministry of Defense Publishing, 1989.

9 Kaczor C. The Edge of Life: Human Dignity and Contemporary Bioethics. Dordrecht, The Netherlands: Springer, 2005.

10 Kaplan LJ, Tong R. Controlling Our Reproductive Destiny: A Technological and Philosophical Perspective. Cambridge, MA: MIT Press, 1996.

11 Krones T, Schlüter E, Neuwohner E, et al. What is the preimplantation embryo? Soc Sci Med 2006;63:1-20.

12 Singer P. Practical Ethics (2nd edn). Cambridge, UK: Cambridge University Press, 1993;150, 182.

13 Singer P. Abortion. In: Honderich T (ed.), The Oxford Companion to Philosophy. New York, NY: Oxford University Press, 2005;1-2, p.2.

14 Dworkin R. Life's Dominion: An Argument about Abortion, Euthanasia, and Individual Freedom. New York, NY: Vintage Books, 1994.

15 Evans JH, Hudson K. Religion and reproductive genetics: beyond views of embryonic life? J Sci Study Relig 2007;46:565-581.

16 Israeli Central Bureau of Statistics. Selected Data from the New Israel Statistical Abstract No. 61 - 2010 [in Hebrew]. 2010. http://www.cbs.gov.il/reader/newhodaot/hodaa_template. html?hodaa $=201011207$ [accessed 9 January 2011].

17 Evans JH. Multi-organizational fields and social movement organization frame content: the religious pro-choice movement. Sociol Inq 1997;67:451-469.

18 Hoffmann JP, Miller AS. Social and political attitudes among religious groups: convergence and divergence over time. J Sci Study Relig 1997;36:52-70.

19 Rapp R. Testing Women, Testing the Fetus: The Social Impact of Amniocentesis in America. London, UK and New York, NY: Routledge, 1999.

20 Singer E, Corning AD, Antonucci T. Attitudes toward genetic testing and fetal diagnosis, 1990-1996. J Health Soc Behav 1999;40:429-445.

21 Remennick L. The quest for the perfect baby: why do Israeli women seek prenatal genetic testing? Sociol Health Illn 2006;28:21-53.

22 Stoler-Liss S. 'Mothers birth the nation': the social construction of Zionist motherhood in wartime in Israeli parents' manuals. Nashim 2003;6(Fall):104-118.
23 Weiss M. The Chosen Body: The Politics of the Body in Israeli Society. Stanford, CA: Stanford University Press, 2002.

24 Wertz D. Eugenics is alive and well: a survey of genetic professionals around the world. Sci Context 1998;11:493-510.

25 Shapira A. 'Wrongful life' suits by defective newborns for faulty genetic counseling. In: The Human Genome Project: Legal, Social and Ethical Implications - Proceedings of an International Workshop. Jerusalem, Israel: The Israel Academy of Sciences and Humanities, 1997;22-29.

26 Rimon-Zarfaty N, Raz A. Abortion committees as agents of eugenics: medical and public views on selective abortion following mild or likely fetal pathology. In: Birenbaum-Carmeli D, Carmeli YS (eds), Kin, Gene, Community: Reproductive Technologies Among Jewish Israelis. Oxford, UK and New York, NY: Berghahn Books, 2010.

27 Gross ML. After feticide: coping with late-term abortion in Israel, Western Europe, and the United States. Camb Q Healthc Ethics 1999;8:449-462.

28 Amir D, Shoshi N. Feminism and women's empowerment in Israel: the abortion policy as a case study [in Hebrew]. In: Ajzenstadt M, Mundlak G (eds), Empowerment on Trial. Tel Aviv, Israel: Tel Aviv University, 2008;279-313.

29 Weiner N, Hashiloni-Dolev Y. On fetuses and relations: the practice of relational ethics in genetic counseling and the management of high risk pregnancy and the standing of the fetus in Israel [in Hebrew]. Israeli Soc 2009;11:65-88.

30 Steinberg A. Jewish perspectives. In: Blazer S, Zimmer EZ (eds), The Embryo Scientific Discovery and Medical Ethic. Basel, Switzerland: Karger, 2005;21-39.

31 Kalfoglou A, Suthers K, Scott J, et al. Reproductive Genetic Testing: What America Thinks. Washington, DC: Genetics and Public Policy Center, 2004.

32 Kelley J, Evans M. When does human life begin? Australas Sci 2002;23:27-29.

33 Glendon MA. Abortion and Divorce in Western Law: American Failures, European Challenges. Cambridge, MA: Harvard University Press, 1987.

34 Israeli Ministry of Health. The General Office Notice Regarding Abortion Committees at the Stage of Viability [in Hebrew]. Jerusalem, Israel: Israeli Ministry of Health, 2007. http://www. health.gov.il/download/forms/a3115_mk23_07.pdf [accessed 9 January 2011].

35 Strasberg-Cohen $\mathrm{T}$. The status of the embryo under Israeli law [in Hebrew]. Med Law 2003;28:8-14.

36 Cranage A. No Consensus on When Human Life Begins. Bio News 482:2008. http://www.bionews.org.uk/page_13559.asp [accessed 8 April 2010].

37 Addelson KP. The emergence of the fetus. In: Morgan LM, Meredith W, Michaels MW (eds), Fetal Subjects, Feminist Positions. Philadelphia, PA: University of Pennsylvania Press, 1999;26-42.

38 Luker K. Abortion and the Politics of Motherhood. Berkeley, CA: University of California Press, 1985.

39 Prainsack B. 'Natural forces' - the regulation of genomics in Israel. In: Glasner P, Atkinson P, Greenslade H (eds), New Genetics, New Social Formations. London, UK: Routledge, 2007;231-252.

40 Barilan MY. 'Tza'ar Gufa Kodem' (Her pain prevails): selective abortions in the Halacha (the Jewish religious law) and in the Israeli law [in Hebrew]. In: Davies J, Sahar A (eds), The Right to Life With No Malformation: From Embryo Formation to Human Being: Scientific, Ethical and Legal Aspects. Tel Aviv, Israel: Dionon, Probook Publication, 2007;81-135. 
41 Berkovitch N. Motherhood as a national mission: the construction of womanhood in the legal discourse in Israel. Womens Stud Int Forum 1997;20:605-619.

42 Kahn SM. Reproducing Jews: A Cultural Account of Assisted Conception in Israel. Durham, NC: Duke University Press, 2000.
43 Prainsack B, Firestine O. 'Science for survival': biotechnology regulation in Israel. Sci Pub Pol 2006;33:33-46.

44 Casper MJ. At the margins of humanity: fetal positions in science and medicine. Sci Technol Human Values 1994;19: 307-323, p.317.

Appendix 1 The full list of stages about which participants were asked in the questionnaire (please note that in Hebrew there is only one word for both embryo and fetus, therefore in the English translation we use only the word fetus)

1. The cell cluster, immediately post-insemination of the ovum in a Petri dish in a fertility laboratory, prior to implanting the fertilised ovum in the womb.

2. The cell cluster, frozen and preserved in a fertility laboratory that can be thawed and potentially implanted in the womb.

3. The cell cluster, immediately after fertilisation of the ovum and the sperm inside the female body, prior to the implantation of the fetus in the womb and prior to the delay in menstruation (Week 2 of pregnancy).

4. The implantation of the fetus in the womb walls and the delay in menstruation.

5. Fetal heartbeats can be tracked (Week 8 of pregnancy).

6. Appearance of human morphology - the fetus acquires more or less human features (Week 10 of pregnancy).

7. All functional systems exist and the pregnant woman is beginning to feel the movements of the fetus. At this stage, the fetus undergoes amniocentesis (Weeks 16-20 of pregnancy).

8. The stage of viability, meaning that the fetus can survive independently outside of the mother's body (Weeks 23-24 of pregnancy).

9. It is possible to estimate the fetus' weight at birth (Week 32 of pregnancy).

10. A newborn baby. 